\title{
Tetrahydrobiopterin Restores Endothelial Function in Hypercholesterolemia
}

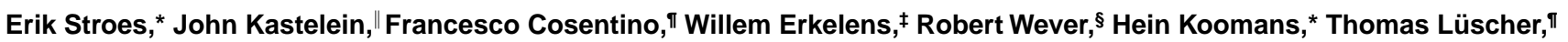 \\ and Ton Rabelink* \\ *Department of Nephrology, ${ }^{\ddagger}$ Department of Internal Medicine, and ${ }^{\S}$ Department of Clinical Chemistry, University Hospital Utrecht, \\ Utrecht, The Netherlands; "Department of Vascular Medicine, University Medical Center, Amsterdam, The Netherlands; \\ and ${ }^{\mathbb{T}}$ Cardiovascular Research, University Hospital, Bern, Switzerland
}

\begin{abstract}
In hypercholesterolemia, impaired nitric oxide activity has been associated with increased nitric oxide degradation by oxygen radicals. Deficiency of tetrahydrobiopterin, an essential cofactor of nitric oxide synthase, causes both impaired nitric oxide activity and increased oxygen radical formation. In this study we tested whether tetrahydrobiopterin deficiency contributes to the decreased nitric oxide activity observed in hypercholesterolemic patients. Therefore, L-mono-methylarginine to inhibit basal nitric oxide activity, serotonin to stimulate nitric oxide activity, and nitroprusside as endothelium-independent vasodilator were infused in the brachial artery of 13 patients with familial hypercholesterolemia and 13 matched controls. The infusions were repeated during coinfusion of L-arginine $(200 \mu \mathrm{g} / \mathrm{kg} / \mathrm{min})$, tetrahydrobiopterin $(500 \mu \mathrm{g} / \mathrm{min})$, or the combination of both compounds. Forearm vasomotion was assessed using forearm venous occlusion plethysmography and expressed as ratio of blood flow between measurement and control arm (M/C ratio). Tetrahydrobiopterin infusion alone did not alter $\mathrm{M} / \mathrm{C}$ ratio. Both the attenuated L-mono-methyl-arginine-induced vasoconstriction as well as the impaired serotonin-induced vasodilation were restored in patients during tetrahydrobiopterin infusion. Tetrahydrobiopterin had no effect in controls. In conclusion, this study demonstrates restoration of endothelial dysfunction by tetrahydrobiopterin suppletion in hypercholesterolemic patients. (J. Clin. Invest. 1997. 99:41-46.) Key words: atherosclerosis - nitric oxide - tetrahydrobiopterin $\bullet$ hypercholesterolemia $\bullet$ L-arginine
\end{abstract}

\section{Introduction}

Evidence is accumulating that nitric oxide $(\mathrm{NO})^{1}$ is a major determinant of the antiatherosclerotic properties of the endothe-

Address correspondence to Dr. T.J. Rabelink, F 03.226, Dept. of Nephrology and Hypertension, University Hospital Utrecht, Heidelberglaan 100, 3584 CX Utrecht, The Netherlands. Phone: 31302507375; FAX: 31-302543492.

Received for publication 25 June 1996 and accepted in revised form 1 November 1996.

1. Abbreviations used in this paper: $\mathrm{BH} 4$, tetrahydrobiopterin; $\mathrm{FBF}$, forearm blood flow; 5-HT, serotonin; L-NMMA, L-mono-methylarginine; $\mathrm{M} / \mathrm{C}$ ratio, ratio of forearm blood flow between measurement and control arm; NO, nitric oxide; NOS, nitric oxide synthase; SNP, sodium nitroprusside.

J. Clin. Invest.

(C) The American Society for Clinical Investigation, Inc.

0021-9738/97/01/0041/06 \$2.00

Volume 99, Number 1, January 1997, 41-46 lium $(1,2)$. All major risk factors for atherosclerotic vascular disease, including hypercholesterolemia, have been associated with impaired NO activity (3-8). The underlying defect in impaired NO activity may involve both decreased formation (9) as well as increased degradation of NO, by reaction with superoxide (10). Indeed, in several in vitro models increased oxygen radical production has been demonstrated during hypercholesterolemia (11-13). It was proposed recently that enhanced oxygen radical production may be caused by nitric oxide synthase (NOS) itself. This is supported by observations showing that both deendothelialization (12) and infusion of the selective NOS antagonist, nitro-L-arginine (13), could not only prevent NO formation, but could also inhibit increased formation of oxygen radicals. In the presence of a deficiency of tetrahydrobiopterin (BH4), an essential cofactor of NOS (14, 15), uncoupling of the L-arginine-NO pathway is observed, which results in increased formation of oxygen radicals by NOS in vitro $(15,16)$. In addition, BH4 depletion has been shown to decrease NO production (9). Therefore, we hypothesized that decreased NO-dependent vasodilation in hypercholesterolemia could be related to a relative deficiency of $\mathrm{BH} 4$, resulting in the aforementioned functional disturbance of NOS. If so, this hypothesis may provide the basis for a novel therapeutic approach to early atherosclerosis.

In this study the first objective was to observe whether $\mathrm{BH} 4$ could improve basal and/or receptor-mediated NO activity in hypercholesterolemic patients. Therefore, we investigated the L-mono-methyl-arginine (L-NMMA)-induced vasoconstrictor response and the serotonin (5-HT)-induced vasodilator response both before and after $\mathrm{BH} 4$ infusion. The second objective was to observe whether $\mathrm{BH} 4$ infusion could improve the altered enzyme kinetics of NOS. In hypercholesterolemia, $\mathrm{L}$-arginine has been shown to be rate limiting in the L-arginine-NO pathway $(3,17)$. Presently, we investigated whether infusion of L-arginine still exerted an ameliorative effect on $\mathrm{NO}$ activity after suppletion of $\mathrm{BH} 4$.

\section{Methods}

Patients. Studies were performed in 13 patients ( 9 males), mean age 32 (4) yr, with definite familial hypercholesterolemia, characterized by LDL-cholesterol of $4.5 \mathrm{mmol} /$ liter or more, VLDL-cholesterol of $2.0 \mathrm{mmol}$ or less, and a family history of premature atherosclerosis and/or tendon xanthomata (18). In the majority of these familial hypercholesterolemia patients, moreover, a molecular diagnosis was established. None had clinical signs of atherosclerosis on physical examination and ECG. Patients did not smoke. Mean plasma cholesterol averaged 8.7 (1.2) $\mathrm{mmol} / \mathrm{liter}$. Mean arterial pressure was 85 (2) $\mathrm{mmHg}$, body mass index was $25.0(0.9) \mathrm{kg} / \mathrm{m}^{2}$, and forearm volume was 1,201 (66) ml. Control studies were performed in 13 sex- (9 males) and age-matched [mean age 28 (2) yr] control subjects. Control subjects did not smoke. Mean plasma cholesterol was $4.0(0.5)$ $\mathrm{mmol} / \mathrm{liter}$. Mean arterial pressure averaged 82 (2) $\mathrm{mmHg}$, body mass index was $23.4(0.6) \mathrm{kg} / \mathrm{m}^{2}$, and mean forearm value was $1,181(58) \mathrm{ml}$. 
Protocol. Vascular function in the forearm was studied $2 \mathrm{wk}$ after cessation of maintenance lipid-lowering medication in patients. $12 \mathrm{~h}$ before the forearm studies, all subjects refrained from drinking alcohol or caffeine-containing beverages. The study protocol was approved by Utrecht University Hospital Ethics Committee for study in human beings. Patients and subjects all gave written informed consent after explanation of the protocol.

The experiments were performed in a temperature controlled room $\left(22-24^{\circ} \mathrm{C}\right)$. Subjects were in supine position with both forearms resting slightly above the level of the heart. A 22-gauge needle was inserted into the brachial artery after local anesthesia. Forearm blood flow (FBF) was measured in both arms at 15-s intervals using straingauge, venous occlusion plethysmography with a microcomputerbased R-wave triggered system for on-line, semicontinuous monitoring (19). Upperarm cuffs were inflated to $45 \mathrm{mmHg}$. During FBF measurement the hands were excluded from the circulation by wrist cuffs, inflated $40 \mathrm{mmHg}$ above systolic blood pressure. Baseline measurements were performed at least $45 \mathrm{~min}$ after cannulation of the brachial artery. Between infusions, a break of at least 20 min was applied to allow FBF to recover before each subsequent infusion. The following substances were infused: 5-HT (Sigma Chemical Co., St. Louis, MO), sodium nitroprusside (SNP; Merck, Darmstadt, Germany), L-arginine hydrochloride (Bufa, Uitgeest, The Netherlands), L-NMMA (Sigma Chemical Co.), and (6R)-5,6,7,8-tetrahydro-L-biopterindihydrochloride (BH4; Alexis Corp., Laufelfingen, Switzerland). All solutions were prepared aseptically from sterile stock solutions or ampoules on the day of the study and stored at $4^{\circ} \mathrm{C}$ until use. $\mathrm{BH} 4$ was prepared freshly just before administration using oxygen-free saline.

The infusion schemes are depicted in Fig. 1. In a subgroup of six patients (four males) and six age- and sex-matched controls, 5-HT was administered in a cumulative dose infusion of 0.1 (dose I), 0.3 (dose II), and 1.0 (dose III) ng/kg/min (scheme 1, block A) (3). Steady state vasorelaxation, due to NO release, was reached after $\sim 3.5 \mathrm{~min}$; each dose-infusion lasted for $5 \mathrm{~min}$. Endothelium-independent vasodilation was assessed by infusion of SNP in a cumulative dose of 1 (dose I), 10 (dose II), 30 (dose III), and 100 (dose IV) ng/kg/ min (scheme 1, block B) (3). Steady state vasorelaxation was reached after $1.5 \mathrm{~min}$; each dose-infusion lasted for $3 \mathrm{~min}$. Basal NO activity was estimated by assessment of vasoconstrictor response to cumulative dose infusion of L-NMMA at a dose of 7.5 (dose I), 15 (dose II), and 30 (dose III) $\mu \mathrm{g} / \mathrm{kg} / \mathrm{min}$ for 5 min per dose (scheme 1, block C), where the latter has been shown to cause near maximal arterial contraction $(20,21)$. In the first infusion scheme, infusion blocks A and B were infused in randomized order, followed by block $\mathrm{C}$. Next, BH4 (scheme 1, block D) was infused at a rate of 10 (dose I), 100 (dose II), 500 (dose III), and 1,000 (dose IV) $\mu \mathrm{g} / \mathrm{min}$ for $5 \mathrm{~min}$ per dose. These dosages were chosen to achieve calculated plasma concentrations in the forearm $(3,22,23)$ of, respectively, $1,10,50$, and $100 \mu \mathrm{M}$, since in in vitro research maximal NO production by endothelial NOS (NOSIII) was reached at $\mathrm{BH} 4$ concentrations ranging from 10 to $100 \mu \mathrm{M}$ (24). Finally, the first three infusion blocks were repeated during coinfusion of BH4 (dose III $=500 \mu \mathrm{g} / \mathrm{min})$ (scheme 1, blocks E-G).

In a subgroup of seven patients (five males) and seven age- and sex-matched controls a slightly modified infusion scheme was used to assess whether L-arginine during BH4 infusion had an additional effect on endothelium-dependent vasomotion and to find out whether an effect of BH4 remained or disappeared after cessation of BH4 infusion. L-arginine was infused at a dose of $200 \mu \mathrm{g} / \mathrm{kg} / \mathrm{min}$, which has been reported to enhance metacholine-stimulated endothelial vasodilation in hypercholesterolemia (25). Thus, after infusion of SNP with saline (Fig. 1, scheme 2, block A), 5-HT was infused during coinfusion of, respectively, saline (block B), L-arginine (block C), BH4 (block D), and $\mathrm{BH} 4$ in combination with L-arginine (block $\mathrm{E}$ ). Next, SNP infusion was repeated during coinfusion of BH4 in combination with L-arginine (block F). Finally, after cessation of both BH4 and L-arginine infusion for $20 \mathrm{~min}, 5-\mathrm{HT}$ infusion was repeated during coinfusion of saline (block $\mathrm{G}$ ).
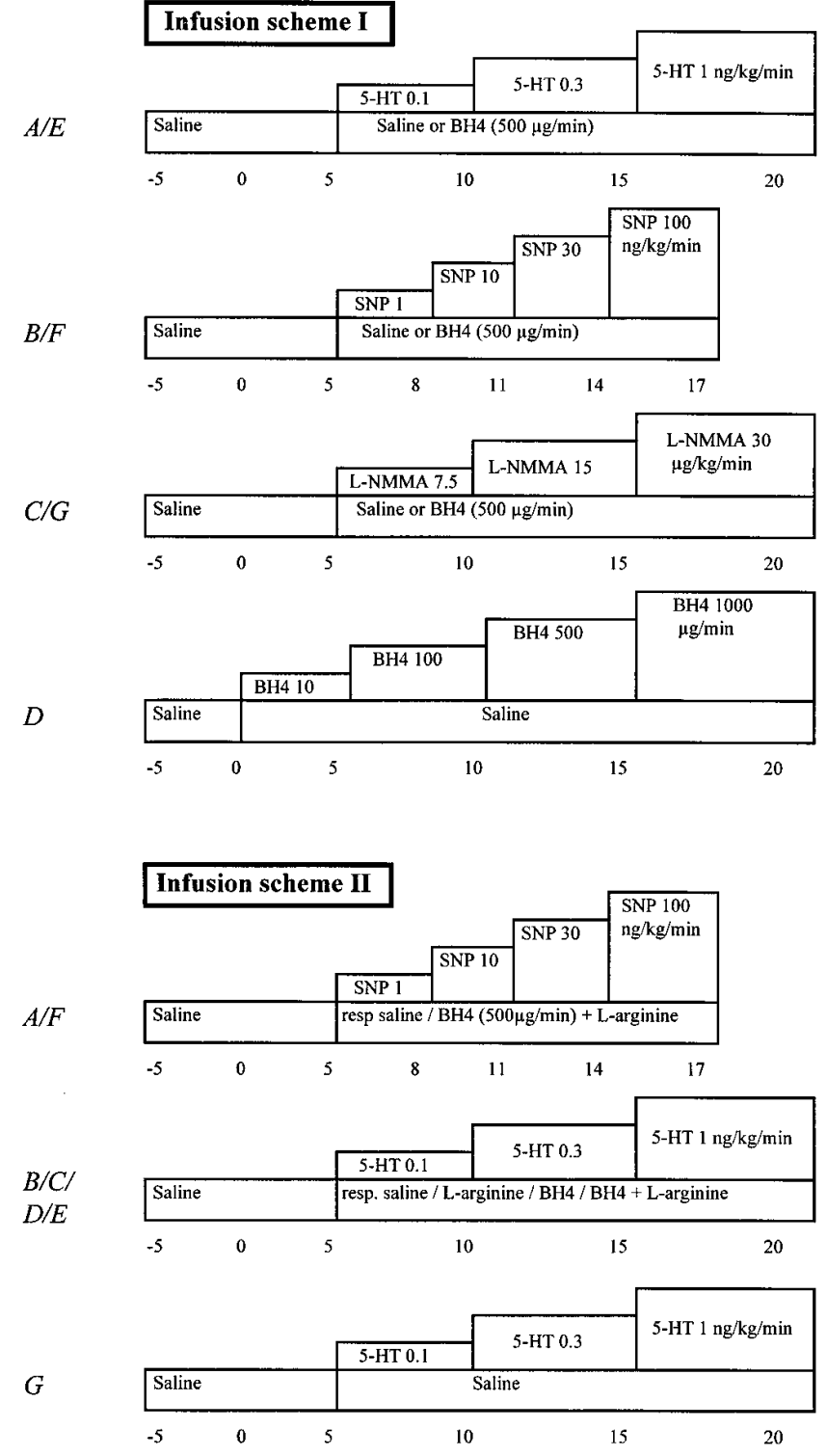

Figure 1. Infusion schemes. (Infusion scheme 1) Cumulative dose infusions of 5-HT $(A / E)$, SNP $(B / F)$, and the NOS inhibitor, L-NMMA $(C / G)$, were performed during, respectively, saline $(A / B / C)$ and $\mathrm{BH} 4$ $(E / F / G)$ coinfusion. (Infusion scheme 2) Cumulative dose-infusion of SNP $(A)$ was followed by cumulative dose-infusion of 5-HT during coinfusion of, respectively, saline $(B)$, L-arginine $(C), \mathrm{BH} 4(D)$ and $\mathrm{BH} 4$ with L-arginine $(E)$. Then, cumulative dose-infusion of SNP $(F)$ was repeated during $\mathrm{BH} 4$ infusion with $\mathrm{L}$-arginine. Finally, $\sim 20 \mathrm{~min}$ after cessation of L-arginine and BH4 infusion, cumulative dose-infusion of 5-HT was repeated $(G)$.

Analysis. FBF was expressed as $\mathrm{ml} / 100 \mathrm{ml}$ forearm tissue/min. During each infusion step the final six values of FBF from both measurement and control arm were used to calculate the mean FBF and the ratio of FBF between measurement and control arm $(\mathrm{M} / \mathrm{C}$ ratio [26]). From the subsequent M/C ratio, curves were constructed (Figs. 2-4). Results are expressed as means (SE).

Differences between $\mathrm{M} / \mathrm{C}$ ratio curves during coinfusion of saline versus, respectively, $\mathrm{BH} 4$, L-arginine, or the combination of latter compounds, were tested using a repeated measures two-way ANOVA. Differences in $\mathrm{M} / \mathrm{C}$ ratio curves between patients and controls were evaluated using two-way ANOVA where the interaction ratio indicated differences between curves. Alterations in absolute FBF upon 
Controls

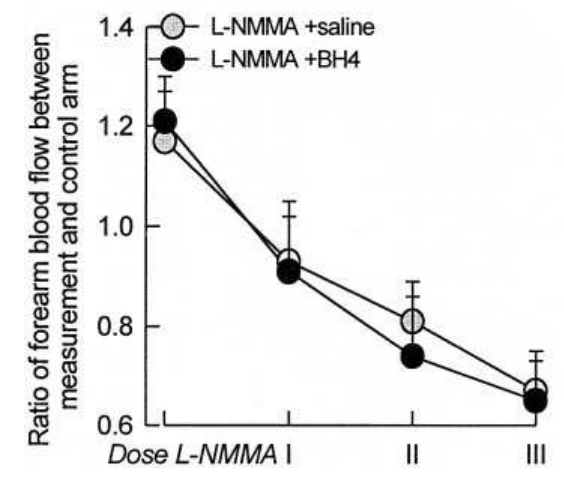

Patients

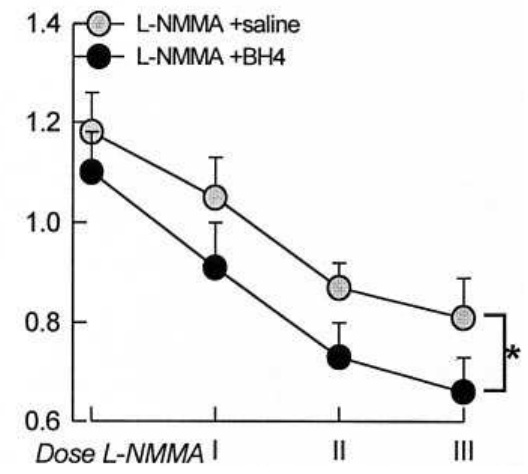

Figure 2. Effect of BH4 on basal NO activity. The decrease in $\mathrm{M} / \mathrm{C}$ ratio upon L-NMMA infusion was unaltered by $\mathrm{BH} 4$ in controls $(n=13)$. In patients $(n=13)$, L-NMMA during BH4 induced a larger reduction in $\mathrm{M} / \mathrm{C}$ ratio compared with L-NMMA during saline. $* P<0.05$ L-NMMA response curve during saline vs. during $\mathrm{BH} 4$. infusion of the various agonists compared with baseline FBF were tested using one-way repeated measures ANOVA. If variance ratios reached statistical significance, differences between the means were analyzed with the Student-Newman-Keul's test for $P<0.05$.

\section{Results}

Influence of $\mathrm{BH} 4$ on baseline vasomotion. Upon cumulative dose-infusion of BH4, basal FBF was not significantly altered in either patients $(n=6)$ or control subjects $(n=6)$ [flow patients from $2.6(0.4)$ to $2.8(0.4)$ (NS); in controls from $2.5(0.3)$ to $2.7(0.4)(\mathrm{NS}) \mathrm{ml} / 100 \mathrm{ml}$ forearm tissue/min; both not significantly different from baseline]. Accordingly, the $\mathrm{M} / \mathrm{C}$ ratios were unaltered by $\mathrm{BH} 4$ coinfusion.

Influence of $\mathrm{BH} 4$ on endothelium-dependent, basal $\mathrm{NO}$ activity. In control subjects $(n=6)$ the decrease in FBF upon
L-NMMA infusion (30 $\mu \mathrm{g} / \mathrm{kg} / \mathrm{min})$ was 38 (3)\% during saline [FBF from $3.0(0.4)$ to $1.9(0.3)(P<0.05) \mathrm{ml} / 100 \mathrm{ml}$ forearm tissue/min] compared with 40 (3)\% during BH4 [FBF from 3.2 $(0.4)$ to $1.9(0.2)(P<0.05)](\mathrm{M} / \mathrm{C}$ ratio curves saline vs. BH4 NS; Fig. 2). In patients $(n=6)$ the decrease in FBF upon L-NMMA was 32 (3)\% during saline [FBF from $2.9(0.4)$ to $2.0(0.3)(P<$ $0.05)$ ] compared with 41 (2)\% during $\mathrm{BH} 4$ [FBF from $3.1(0.4)$ to $1.8(0.3)(P<0.05)]$. As reflected in the $\mathrm{M} / \mathrm{C}$ ratio curve (Fig. 2), in patients the vasoconstrictor response to L-NMMA was significantly increased during $\mathrm{BH} 4$ compared with saline infusion $(P<0.05)$.

Influence of $\mathrm{BH} 4$ on endothelium-dependent stimulated $\mathrm{NO}$ activity. In control subjects $(n=13)$ coinfusion of BH4 did not significantly alter 5-HT-induced, NO-mediated vasodilation [saline: FBF $2.5(0.2)$ to $6.0(0.6)(P<0.05)$; BH4: FBF 2.5 (0.2) to $6.1(0.7)(P<0.05) \mathrm{ml} / 100 \mathrm{ml}$ forearm tissue/min $)](\mathrm{M} / \mathrm{C}$
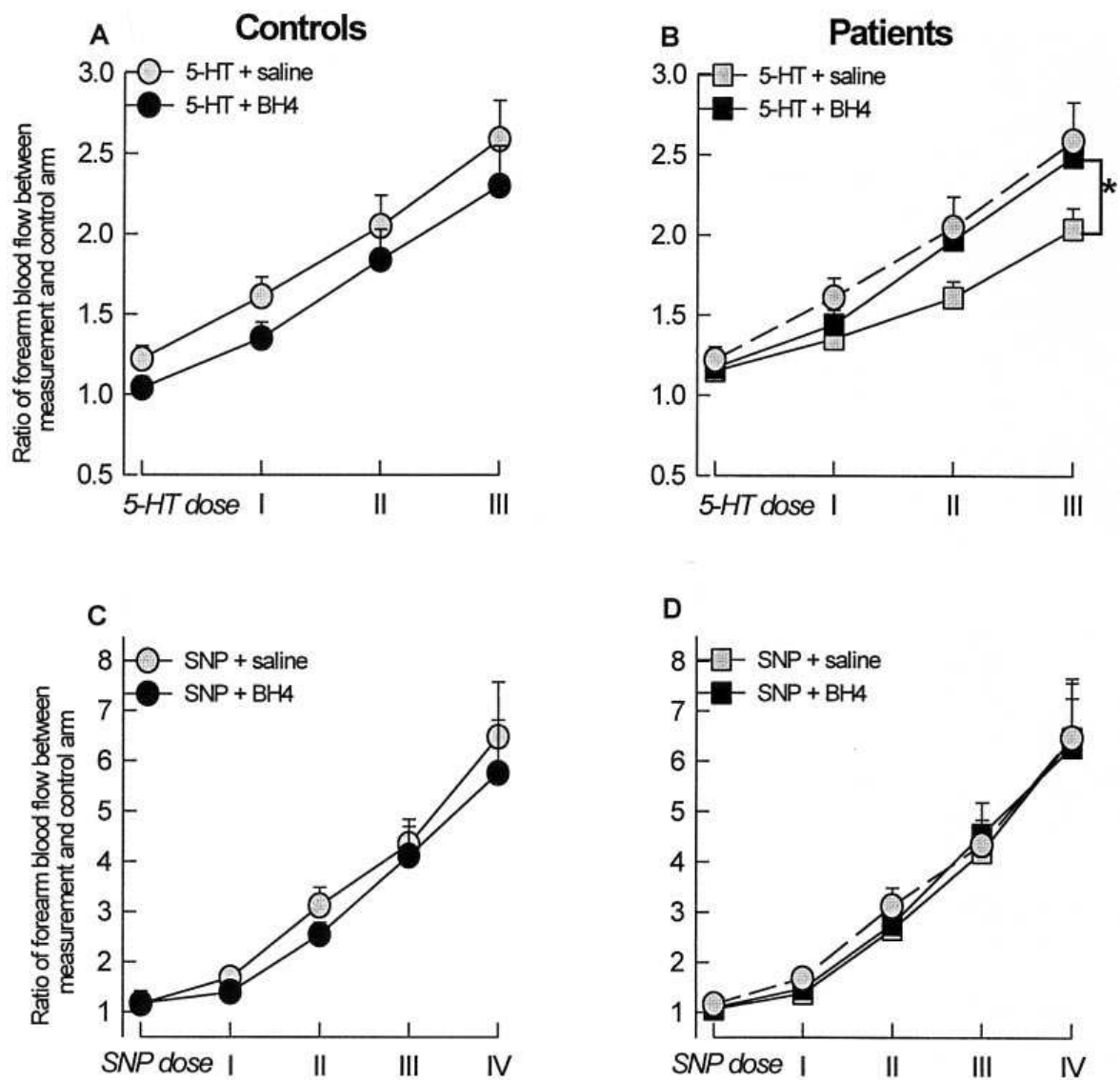

D

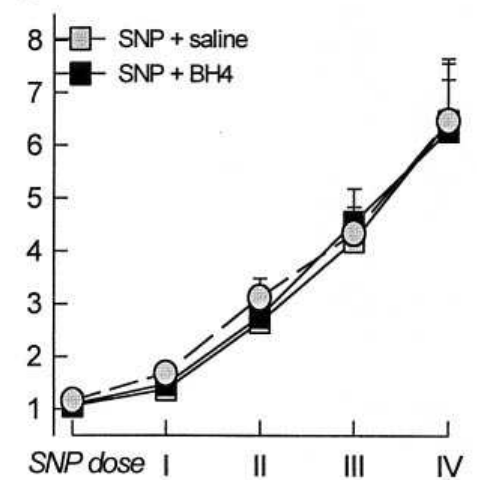

Figure 3. Effect of $\mathrm{BH} 4$ on vasodilator responses. ( $A$ and $B$ ) Whereas $\mathrm{BH} 4$ did not significantly alter 5-HT-induced increase in the $\mathrm{M} / \mathrm{C}$ ratio in controls $(A), \mathrm{BH} 4$ significantly enhanced the 5-HT response in patients $(B)$. The dotted line in $B$ is added as reference value of 5-HT-induced vasodilation in the control group $(A)$. ( $C$ and $D) \mathrm{BH} 4$ did not alter endothelium-independent responses in either controls $(C)$ or patients $(D)$. The dotted line in $D$ is added as reference value of nitroprussideinduced vasodilation in the control group (C). ${ }^{*} P<0.055$-HT response curve during saline vs. BH4. 
ratio curve saline vs. BH4 NS; Fig. 3). In contrast, in patients ( $n=13$ ) 5-HT-induced vasodilation was significantly enhanced by BH4 coinfusion [saline: FBF $2.9(0.2)$ to $5.5(0.5)$ $(P<0.05)$; BH4 $2.9(0.3)$ to $6.7(0.9)(P<0.05) \mathrm{ml} / 100 \mathrm{ml}$ forearm tissue/min] $(\mathrm{M} / \mathrm{C}$ ratio curve saline vs. $\mathrm{BH} 4 ; P<0.05)$. Accordingly, whereas the $\mathrm{M} / \mathrm{C}$ ratio curve for 5-HT in patients was significantly impaired compared with controls $(P<0.05)$, this difference between patients and controls was abolished upon $\mathrm{BH} 4$ coinfusion in patients (NS) (Fig. 3).

In the subgroup of seven controls, 5-HT response [from 2.4 (0.3) to $6.3(1.0)(P<0.05)]$ was not significantly altered by coinfusion of either L-arginine [from $2.5(0.3)$ to $6.2(1.0)(P<$ $0.05)$ ] or L-arginine in combination with $\mathrm{BH} 4$ infusion [from 2.3 (0.3) to $6.3(1.1)(P<0.05)](\mathrm{M} / \mathrm{C}$ ratio curves saline vs. L-arginine with/without BH4 NS). In the subgroup of seven patients, L-arginine enhanced 5-HT response [saline: from $2.9(0.3)$ to $5.8(0.6)(P<0.05)$, L-arginine: from $3.0(0.3)$ to $6.4(0.7)(P<$ $0.05) \mathrm{ml} / 100 \mathrm{ml}$ forearm tissue/min] (M/C ratio curve saline vs. L-arginine, $P<0.05$; Fig. 4). Coinfusion of L-arginine during $\mathrm{BH} 4$ infusion did not have an additional effect on 5-HT-induced vasodilation [from $3.3(0.4)$ to $7.2(1.0)(P<0.05) \mathrm{ml} / 100 \mathrm{ml}$ forearm tissue/min] compared with $\mathrm{BH} 4$ infusion alone [FBF from 2.9 (0.3) to $6.7(0.9)$ ] (M/C ratio curve BH4 versus BH4 with L-arginine, NS). The beneficial effects of BH4 were transient, since $20 \mathrm{~min}$ after cessation of $\mathrm{BH} 4 / \mathrm{L}$-arginine infusion the beneficial effect could no longer be demonstrated [baseline FBF: from 2.9 (0.3) to 5.8 (0.6), cessation of BH4/L-arginine: from $3.1(0.3)$ to $6.1(0.6) \mathrm{ml} / 100 \mathrm{ml}$ forearm tissue/min] $(\mathrm{M} / \mathrm{C}$ ratio curve baseline vs. after cessation of $\mathrm{BH} 4 / \mathrm{L}$-arginine NS; Fig. 4).

Influence of $\mathrm{BH} 4$ on endothelium-independent vasomotion. SNP response was not significantly different between control subjects and patients (see M/C ratio curves, Fig. 3).
BH4 coinfusion had no effect upon SNP-induced vasodilation in either controls [FBF with saline: $2.7(0.4)$ to $15.5(1.9)(P<$ $0.05)$, with BH4 $3.1(0.4)$ to $16.2(2.2)(P<0.05) \mathrm{ml} / 100 \mathrm{ml}$ forearm tissue/min] (M/C ratio curves saline vs. BH4 NS) or patients [FBF with saline: $2.4(0.4)$ to $14.7(1.6)(P<0.05)$, with BH4 $3.1(0.5)$ to $15.3(1.7)(P<0.05)](\mathrm{M} / \mathrm{C}$ ratio curve saline vs. BH4 NS; Fig. 3). Additionally, L-arginine infusion during $\mathrm{BH} 4$ did not alter SNP response in either controls [FBF with saline $2.3(0.3)$ to $14.6(1.5)(P<0.05)$, with $\mathrm{BH} 4+\mathrm{L}$-arginine $3.2(0.3)$ to $15.0(1.4)(P<0.05)](\mathrm{M} / \mathrm{C}$ ratio curves saline vs. BH4 + L-arginine NS) or patients [FBF with saline: $2.8(0.3)$ to $14.2(1.8)(P<0.05)$, with $\mathrm{BH} 4+\mathrm{L}$-arginine $3.2(0.3)$ to 14.2 (1.1) $(P<0.05) \mathrm{ml} / 100 \mathrm{ml}$ forearm tissue/min] $(\mathrm{M} / \mathrm{C}$ ratio curves saline vs. BH4 + L-arginine NS).

\section{Discussion}

In this study it is demonstrated that in hypercholesterolemic patients $\mathrm{BH} 4$ restores the disturbed $\mathrm{NO}$-dependent vasodilation. L-arginine improved NO-dependent vasodilation in these patients, whereas L-arginine caused no further improvement in the presence of $\mathrm{BH} 4$ suppletion. $\mathrm{BH} 4$ and/or L-arginine coinfusion had no effect on endothelium-independent vasodilation in patients, nor on endothelium-dependent and -independent vasodilation in healthy controls.

Effect of BH4 on basal FBF. BH4 infusion by itself did not significantly alter basal FBF in either patients or controls. In in vitro experiments $\mathrm{BH} 4$ has been shown to exert both vasorelaxing (27) as well as vasoconstrictor (28) effects. In these experiments possible confounding factors include the induction of inducible NOS, i.e., NOS-II, during preparation and autooxidation of BH4 (29). Notably, NOS-II has been demonstrated

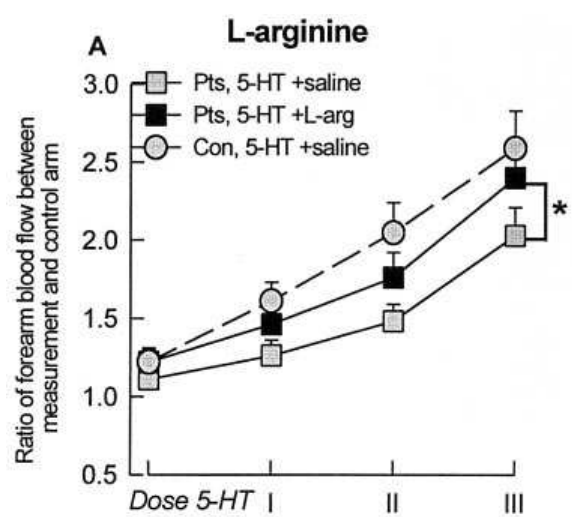

c BH4+L-arginine

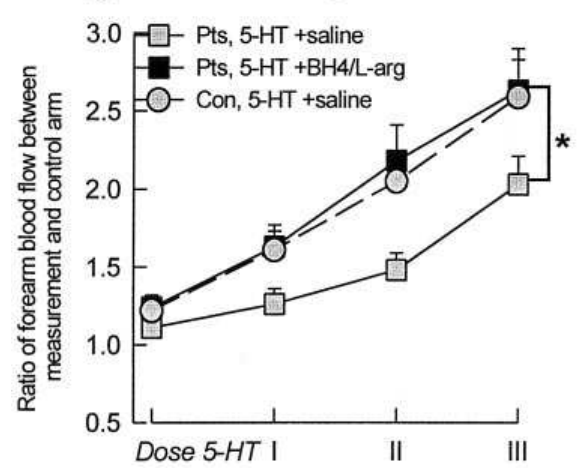

44

Stroes et al.

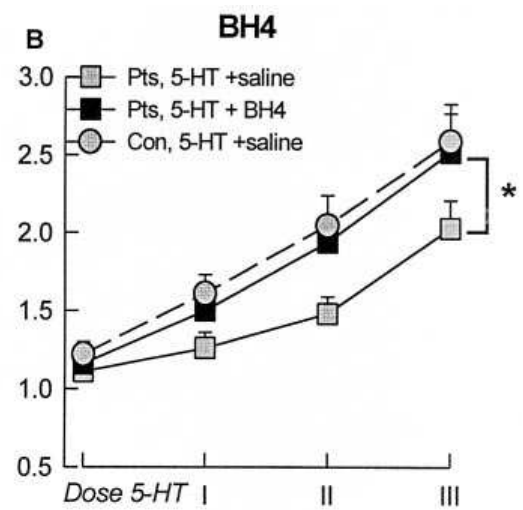

D Cessation of $\mathrm{BH} 4 / \mathrm{L}$-arginine

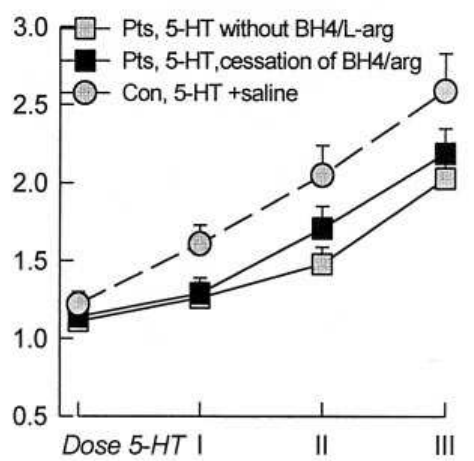

Figure 4. Interaction of $\mathrm{BH} 4$ and L-arginine on NO activity. 5-HT-induced increase in the $\mathrm{M} / \mathrm{C}$ ratio in hypercholesterolemic patients was significantly enhanced by coinfusion of either L-arginine $(A)$, $\mathrm{BH} 4(B)$, and $\mathrm{BH} 4+\mathrm{L}$-arginine $(n=7)$ (C). 20 min after cessation of BH4/L-arginine infusion, the improvement in endothelial response had almost completely disappeared $(D)$. The dotted line is added as reference value of 5-HT-induced vasodilation in the control group. ${ }^{*} P<0.05$; 5-HT response curve during saline vs. during $\mathrm{BH} 4$ and/or $\mathrm{L}$-arginine. $\mathrm{MC}$ ratio curve BH4 (B) versus BH4/L-arg $(C)$ not significantly different. 
to be critically dependent on BH4 availability $(30,31)$. One uncontrolled study reported also vasorelaxing effects of $\mathrm{BH} 4$ in vivo in two healthy subjects (32). However, in that study up to 50 -fold higher dosages were infused.

Effect of BH4 on NO activity. To assess basal NO activity in patients and controls, the vasoconstrictor response to incremental dosages of the specific NOS inhibitor, L-NMMA, was measured. There was a tendency towards a decreased constrictor response to L-NMMA in patients, which did not reach statistical significance compared with healthy controls. However, whereas $\mathrm{BH} 4$ coinfusion did not alter the response in healthy volunteers, the vasoconstrictor response to L-NMMA was significantly enhanced in patients by $\mathrm{BH} 4$. This is compatible with an, albeit mild, degree of impairment in basal NO activity, which can be improved by BH4 suppletion in hypercholesterolemic patients. We also studied vasodilation during stimulation of NO by 5-HT, which in the dosages used elicits selective NO-mediated vasodilation in both hypercholesterolemic patients (3) as well as in controls $(3,22,23)$. Stimulated NO activity was significantly impaired in patients compared with controls, which is in accordance with earlier studies demonstrating impaired endothelial function in patients with hypercholesterolemia $(3,4)$. Coinfusion of BH4 could restore the impaired NO-dependent vasodilation in patients, but had no such effect in controls. Given the improvement of basal NO activity by $\mathrm{BH} 4$, one would also have expected an effect of $\mathrm{BH} 4$ on basal FBF. However, it should be noticed that the forearm model has a limited sensitivity to detect changes in basal flow $(3,7,17)$. Accordingly, only changes in maximal inhibition and receptor stimulation reached significance.

The action of $\mathrm{BH} 4$ proved to be transient, since discontinuation of BH4/L-arginine infusion rapidly resulted in reoccurrence of impaired NO activity. One would expect a longer lasting effect of $\mathrm{BH} 4$ since binding of $\mathrm{BH} 4$ to NOS is tight (16) and NOS has been shown, once bound, to autoregenerate the inactive oxidized form of $\mathrm{BH} 4$, quinonoid dihydrobiopterin, back to the active $\mathrm{BH} 4$ (33). One possible explanation for the short duration could be that the increased production of reactive oxygen species that has been demonstrated during hypercholesterolemia (11-13) results in enhanced oxidation of BH4. Since only reduced $\mathrm{BH} 4$ is active as cofactor for NOS (34), this would limit the duration of action of $\mathrm{BH} 4$ suppletion.

Mechanisms of BH4-induced increase in NO activity in hypercholesterolemia. An improvement in $\mathrm{NO}$ activity by $\mathrm{BH} 4$ suppletion in hypercholesterolemia signifies either increased formation or decreased degradation of NO. Increased formation of $\mathrm{NO}$ upon $\mathrm{BH} 4$ suppletion could well be related to the essential role of BH4 as cofactor for the NOS enzyme (34). BH4 increases NOS activity by serving as electron donor for the hydroxylation of L-arginine $(14,35)$, by serving as allosteric factor, which helps to stabilize the active dimeric state of the NOS enzyme $(36,37)$, or by inhibiting the direct negative feedback inhibition of NO upon NOS $(29,34)$. If the increased NO activity can be explained by enhanced NO formation, one has to assume that hypercholesterolemia is accompanied by an absolute or relative deficiency of BH4. The background for such a deficiency is not clear. Perhaps, the enhanced oxidative stress in hypercholesterolemia accelerates oxidation of BH4 $(29,38)$. As mentioned earlier, this option would also explain the transient effect of $\mathrm{BH} 4$ suppletion on NOS activity. BH4 deficiency may also be explained by the observation that in human endothelial cells NOS-III becomes critically dependent upon
BH4 availability in the presence of inflammatory cytokines (39). Interestingly, in vivo hypercholesterolemia (40) and atherosclerosis (41) have been shown to be accompanied by inflammatory changes of the endothelium with local release of cytokines. However, so far this inflammatory response has been established for coronary conduit arteries and it remains to be established whether this also holds true for resistance vessels.

It is not very likely that the observed effect of BH4 can be explained by an effect of BH4 on NOS-II, which may be present in vascular smooth muscle cells and macrophages in the vascular wall and which in vitro has been shown to be dependent upon $\mathrm{BH} 4$ concentration $(30,31)$. In this respect, 5-HT induces a receptor-operated calcium-mediated increase in NOS-III activation, whereas it has no effect on the calciumindependent NOS-II.

Apart from increased $\mathrm{NO}$ production by $\mathrm{BH} 4$, decreased degradation of NO may also explain the observed increase in $\mathrm{NO}$ activity. A main pathway of inactivation of NO involves its reaction with superoxide anion (10). Increased breakdown of $\mathrm{NO}$ could also be explained from a BH4 deficiency. During $\mathrm{BH} 4$ deficiency, NOS-III has been shown to produce, besides $\mathrm{NO}$, a disproportionate amount of oxygen radicals $(15,16)$. $\mathrm{BH} 4$ suppletion may thus restore $\mathrm{NO}$ activity by decreasing oxygen radical formation. Restoration of endothelial function by an NOS-unrelated action of $\mathrm{BH} 4$ seems less likely. A recent study showed that BH4 by itself, in the absence of NOS, may in fact generate superoxide (28) and thus decrease NO activity.

$\mathrm{BH} 4$ and the effect of $\mathrm{L}$-arginine. $\mathrm{L}$-arginine has been shown to ameliorate impaired NO activity in hypercholesterolemia. Interestingly, in vivo L-arginine concentrations appear to be well above the $K_{\mathrm{m}}$ of NOS for L-arginine $(42,43)$. The observation that L-arginine seems to be rate-limiting under these conditions, despite saturating concentrations of L-arginine, has been referred to as the "L-arginine paradox" (44). In the present study $\mathrm{BH} 4$ suppletion abolished the rate limiting role of L-arginine in hypercholesterolemic patients. Interestingly, $\mathrm{BH} 4$ has also been demonstrated to increase substrate affinity of NOS for L-arginine $(45,46)$. It is tempting to speculate that decreased affinity of NOS for L-arginine due to $\mathrm{BH} 4$ deficiency contributes to the L-arginine paradox in hypercholesterolemia.

Summary. Endothelial dysfunction is an event which occurs early in the development of cardiovascular disease, even before the onset of macroscopical structural changes (47-49). In the present study it is shown that endothelial dysfunction can be restored in patients with hypercholesterolemia by $\mathrm{BH} 4$ suppletion, at a stage where macrovascular disease has not yet occurred. These data not only underscore the relevance of $\mathrm{BH} 4$ as crucial cofactor for NO synthesis in vivo in humans, but also may initiate research into new therapeutic approaches to prevent initiation and progression of cardiovascular disease in hypercholesterolemia.

\section{Acknowledgments}

We gratefully acknowledge Dr. Fred Schobben for preparation of the BH4.

Dr. Ton Rabelink is supported by a fellowship of the Royal Dutch Academy of Sciences (KNAW). This work was supported by the Dutch Kidney Foundation (grant C 93.1300). Dr. John Kastelein is a clinical investigator of the Dutch Heart Foundation. 


\section{References}

1. Anggard, E. 1994. Nitric oxide: mediator, murderer and medicine. Lancet. 343:1199-1206

2. Luscher, T.F., and G. Noll. 1995. The pathogenesis of cardiovascular disease: role of the endothelium as target and mediator. Atherosclerosis. 188(Suppl.):S81-S90.

3. Stroes, E.S.G., H.A. Koomans, T.W.A. de Bruin, and T.J. Rabelink. 1995. Vascular function in the forearm of hypercholesterolaemic patients off and on lipid-lowering medication. Lancet. 346:467-471.

4. Creager, M., J.P. Cooke, M.E. Mendelsohn, S.J. Gallagher, S.M. Coleman, J. Loscalzo, and V.J. Dzau. 1990. Impaired vasodilation of forearm resistance vessels in hypercholesterolemic humans. J. Clin. Invest. 86:228-234.

5. Panza, J.A., C.E. Garcia, C.M. Kilcoyne, A.A. Quyyumi, and R.O. Cannon. 1995. Impaired endothelium-dependent vasodilation in patients with essential hypertension. Circulation. 91:1732-1738.

6. Johnstone, M.T., S.J. Creager, K.M. Scales, J.A. Cusco, B.K. Lee, and M.A. Creager. 1993. Impaired endothelium-dependent vasodilation in patients with insulin-dependent vasodilation. Circulation. 88:2510-2516.

7. Ting, H.T., F.K. Timimi, K.S. Boles, S.J. Creager, P. Ganz, and M.A. Creager. 1996. Vitamin C improves endothelium-dependent vasodilation in patients with non-insulin-dependent diabetes mellitus. J. Clin. Invest. 97:22-28.

8. Heitzer, T., S. Yla-Herttuala, J. Luoma, S. Kurz, T. Munzel, H. Just, M. Olschewski, and H. Drexler. 1996. Cigarette smoking potentiates endothelial dysfunction of forearm resistance vessels in patients with hypercholesterolaemia. Circulation. 93:1346-1353.

9. Schmidt, K., E.R. Werner, B. Mayer, H. Wachter, and W.R. Kukovetz. 1992. Tetrahydrobiopterin-dependent formation of endothelium-derived relaxing factor (nitric oxide) in aortic endothelial cells. Biochem. J. 281:297-300.

10. Huie, R.E., and S. Padmaja. 1993. The reaction of NO with superoxide. Free Radical Res. Commun. 18:195-199.

11. Minor, R.L., P.R. Myers, R. Guerra, J.N. Bates, and D.G. Harrison. 1990. Diet-induced atherosclerosis increases the release of nitrogen oxides from rabbit aorta. J. Clin. Invest. 86:2109-2116.

12. Ohara, Y., T.E. Peterson, and D.G. Harrison. 1993. Hypercholesterolemia increases endothelial superoxide anion production. J. Clin. Invest. 91: 2546-2551.

13. Pritchard, K.A., L. Groszek, D.M. Smalley, W.C. Sessa, M. Wu, P. Villalon, M.S. Wolin, and M.B. Stemerman. 1995. Native low-density lipoprotein increases endothelial cell nitric oxide synthase generation of superoxide anion. Circ. Res. 77:510-518.

14. Mayer, B., M. John, E.R. Werner, H. Wachter, G. Schultz, and E. Bohme. 1991. Brain nitric oxide synthase is a biopterin- and flavin-containing multifunctional oxido-reductase. FEBS Lett. 288:187-191.

15. Heinzel, B., M. John, P. Klatt, E. Bohme, and B. Mayer. 1992. $\mathrm{Ca}^{2+}$ calmodulin dependent formation of hydrogen peroxide by brain nitric oxide synthase. Biochem. J. 281:627-630.

16. Cosentino, F., and Z. Katusic. 1995. Tetrahydrobiopterin and dysfunction of endothelial nitric oxide synthase in coronary arteries. Circulation. 91: 139-144.

17. Drexler, H., A. Zeiher, K. Meinzer, and H. Just. 1991. Correction of endothelial dysfunction in coronary microcirculation of hypercholesterolaemic patients by L-arginine. Lancet. 338:1546-1550.

18. Goldstein, J.L., and M.S. Brown. 1983. Familial hypercholesterolemia. In The Metabolic Basis of Inherited Disease. $5^{\text {th }}$ ed. J.B. Stanbury, J.B. Wijngaarden, D.S. Frederickson, J.L. Goldstein, and M.S. Brown, editors. McGrawHill, New York. 672-712.

19. Chang, P.C., R. Verlinde, T.A. Bruning, and P. van Brummelen. 1988. A microcomputer-based R-wave triggered system for hemodynamic measurements in the forearm. Comput. Biol. Med. 18:157-163.

20. Calver, A., J. Collier, and P. Vallence. 1992. Inhibition and stimulation of nitric oxide in the human forearm bed of patients with insulin-dependent diabetes. J. Clin. Invest. 90:2448-2454.

21. Chowienczyk, P.J., J.R. Cockroft, and J.M. Ritter. 1995. Inhibition of acetylcholinesterase selectively potentiates $N^{\mathrm{g}}$-monomethyl-L-arginine resistant actions of acetylcholine in human forearm vasculature. Clin. Sci. 88:111-117.

22. Bruning, T.A., P.A. van Zwieten, G.J. Blauw, and P.C. Chang. 1994. No functional involvement of 5-hydroxytryptamine 1a receptors in nitric oxide dependent dilation caused by serotonin in the human forearm vascular bed. $J$. Cardiovasc. Pharmacol. 24:454-461.

23. Stroes, E.S.G., J.A. Joles, P.C. Chang, H.A. Koomans, and T.J. Rabelink. 1995. Impaired endothelial function in patients with nephrotic range proteinuria. Kidney Int. 48:544-550.

24. Chen, P.F., A. Tsai, and K.K. Wu. 1995. Cysteine 99 of endothelial nitric oxide synthase (NOS-III) is critical for tetrahydrobiopterin-dependent NOS-III stability and activity. Biochem. Biophys. Res. Commun. 215:1119-1129.

25. Creager, M.A., S.J. Gallagher, X.J. Girerd, S.M. Coleman, V.J. Dzau, and J.P. Cooke. 1992. L-arginine improves endothelium-dependent vasodilation in hypercholesterolemic humans. J. Clin. Invest. 90:1248-1253.

26. Benjamin, N., A. Calver, J. Collier, B. Robinson, P. Vallence, and D.
Webb. 1995. Measuring forearm blood flow and interpreting the responses to drugs and mediators. Hypertension (Dallas). 25:918-923.

27. Van Amsterdam, J.G.C., and J. Wemer. 1992. Tetrahydrobiopterin induces vasodilation via enhancement of cGMP level. Eur. J. Pharmacol. 215: 349-350.

28. Tsutsui, M., S. Milstein, and Z.S. Katusic. 1996. Effect of tetrahydrobiopterin on endothelial function in canine middle cerebral arteries. Circ. Res. 79:336-342.

29. Davies, M.D., and S. Kaufman. 1993. Products of the tyrosine-dependent oxidation of tetrahydrobiopterin by rat liver phenylalanine hydroxylase. Arch. Biochem. Biophys. 304:9-16.

30. Gross, S.S., and R. Levi. 1992. Tetrahydrobiopterin synthesis. An absolute requirement for cytokine-induced nitric oxide generation by vascular smooth muscle. J. Biol. Chem. 36:25722-25729.

31. Cho, H.J., E. Martin, Q. Xie, and C. Nathan. 1995. Inducible nitric oxide synthase: identification of amino acid residues essential for dimerization and binding of tetrahydrobiopterin. Proc. Natl. Acad. Sci. USA. 92:11514-11518.

32. Schaffner, A., N. Blau, M. Schneemann, J. Steurer, C.S. Edgell, and G. Schoedon. 1994. Tetrahydrobiopterin as another EDRF in man. Biochem. Biophys. Res. Commun. 205:516-523.

33. Witteveen, C.F.B., J. Giovanelli, and S. Kaufman. 1996. Reduction of quinonoid dihydrobiopterin to tetrahydrobiopterin by nitric oxide synthase. $J$. Biol. Chem. 271:4143-4147.

34. Mayer, B., and E. Werner. 1995. In search of a function for tetrahydrobiopterin in the biosynthesis of nitric oxide. Naunyn-Schmiederberg's Arch. Pharmacol. 351:453-463.

35. Tayeh, M.A., and M.A. Marletta. 1989. Macrophage oxidation of L-arginine to nitric oxide, nitrite, and nitrate. Tetrahydrobiopterin is required as a cofactor. J. Biol. Chem. 264:19654-19658.

36. Klatt, P., K. Schmidt, D. Lehner, O. Glatter, H.P. Bachinger, and B. Mayer. 1995. Structural analysis of porcine brain nitric oxide synthase reveals a role for tetrahydrobiopterin and $\mathrm{L}$-arginine in the formation of an SDS-resistant dimer. EMBO (Eur. Mol. Biol. Organ.) J. 14:3687-3695.

37. Nathan, C., and Q. Xie. 1994. Nitric oxide synthases: roles, tolls and controls. Cell. 78:915-918.

38. Harrison, G., and Y. Ohara. 1995. Physiologic consequences of increased vascular oxidant stresses in hypercholesterolemia and atherosclerosis: implications for impaired vasomotion. Am. J. Cardiol. 75:75b-81b.

39. Rosenkranz-Weiss, P., W.C. Sessa, S. Milstein, S. Kaufman, C.A. Watson, and J.S. Pober. 1994. Regulation of nitric oxide synthesis by proinflammatory cytokines in human umbilical vein endothelial cells. Elevations in tetrahydrobiopterin levels enhance endothelial nitric oxide synthase specific activity. $J$. Clin. Invest. 93:2236-2243.

40. Kume, N., M.I. Cybulsky, and M.A. Gimbrone. 1992. Lysophosphatidylcholine, a component of atherogenic lipoproteins, induces mononuclear leukocyte adhesion molecules in cultured human and rabbit arterial endothelial cells. J. Clin. Invest. 90:1138-1144.

41. Gimbrone, M.A. 1995. Vascular endothelium: an integrator of pathophysiologic stimuli in atherosclerosis. Am. J. Cardiol. 75:67B-70B.

42. Hecker, M., W.C. Sessa, H.J. Harris, E. Anggard, and J.R. Vane. 1990. The metabolism of L-arginine and its significance for the biosynthesis of endothelium-derived relaxing factor: cultured endothelial cells recycle L-citrulline to L-arginine. Proc. Natl. Acad. Sci. USA. 87:8612-8616.

43. Arnal, J.F., T. Munzel, R.C. Venema, N.L. James, C.L. Bai, W.E. Mitch, and D.G. Harrison. 1995. Interactions between L-arginine and L-glutamine change endothelial NO production. An effect independent of NO synthase substrate availability. J. Clin. Invest. 95:2565-2572.

44. Forstermann, U., E.I. Closs, J.S. Pollock, M. Nakane, P. Schwarz, I. Gath, and H. Kleinert. 1994. Nitric oxide synthase isoenzymes. Characterization, purification, molecular cloning, and functions. Hypertension (Dallas). 23: $1121-1131$.

45. Nishimura, J.S., P. Martasek, K. McMillan, J.C. Salerno, Q. Liu, S.S Gross, and B.S.S. Masters. 1995. Modular structure of neuronal nitric oxide synthase: localization of the arginine binding site and modulation by pterin. Biochem. Biophys. Res. Commun. 210:288-294.

46. Brand, M.P., S.J.R. Heales, J.M. Land, and J.B. Clark. 1995. Tetrahydrobiopterin deficiency and brain nitric oxide synthase in the hph1 mouse. J. Inher. Metab. Dis. 18:33-39.

47. Zeiher, A.M., H. Drexler, H. Wollschlager, and H. Just. 1991. Modulation of coronary vasomotor tone in humans. Progressive endothelial dysfunction with different early stages of coronary atherosclerosis. Circulation. 83:391-401.

48. Quyyumi, A.A., N. Dakak, N.P. Andrews, S. Husain, S. Arora, D.M. Gilligan, and J.A. Panza. 1995. Nitric oxide activity in the human coronary circulation. Impact of risk factors for coronary atherosclerosis. J. Clin. Invest. 95: $1747-1753$.

49. Reddy, K.G., R.N. Nair, H.M. Sheehan, and J. Hodgson. 1994. Evidence that selective endothelial dysfunction may occur in the absence of angiographic or ultrasound atherosclerosis in patients with risk factors for atherosclerosis. $J$. Am. Coll. Cardiol. 23:833-843. 